\title{
Pasta autonivelante de gesso para utilização como camada de contrapiso
}

Self-levelling gypsum paste for use as a subfloor layer

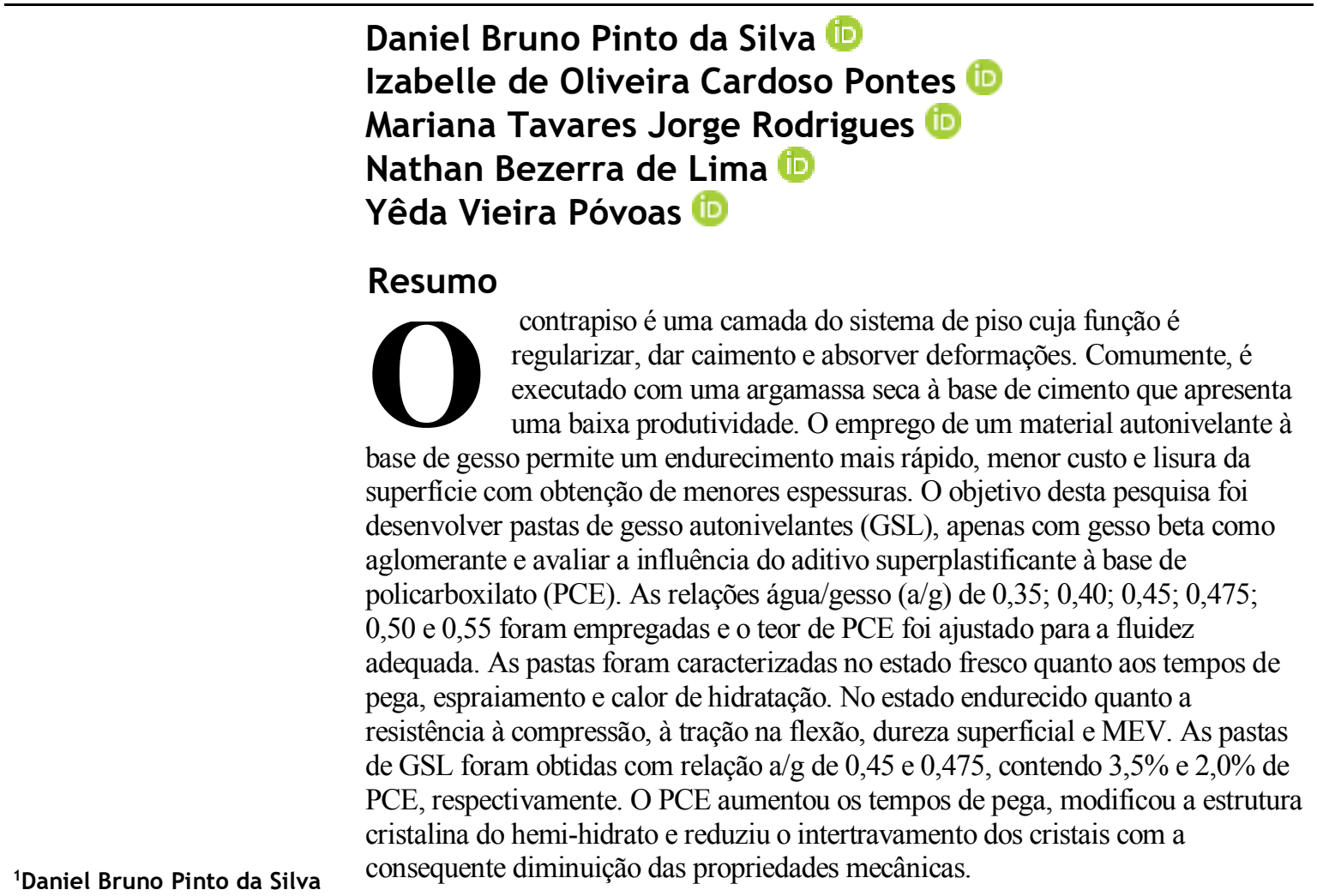

1 Universidade de Pernambuco Recife - PE - Brasil

\section{${ }^{2}$ Izabelle de Oliveira Cardoso \\ Pontes \\ 2Universidade de Pernambuco Recife - PE - Brasil}

${ }^{3}$ Mariana Tavares Jorge Rodrigues

${ }^{3}$ Universidade de Pernambuco Recife - PE - Brasil

${ }^{4}$ Nathan Bezerra de Lima ${ }^{4}$ Universidade de Pernambuco Recife - PE - Brasil

${ }^{5}$ Yêda Vieira Póvoas ${ }^{5}$ Universidade de Pernambuco Recife - PE - Brasil

Recebido em 30/01/20 Aceito em 13/07/20
Palavras-chave: Gesso. Autonivelante. Contrapiso. Policarboxilato. Microestrutura.

\section{Abstract}

The subfloor is a layer of the floor system designed to smooth, level and absorb deformations. Conventionally, subfloors are made of a low-productivity dry cement-based mortar. The use of a self-levelling gypsum-based material allows faster curing, lower cost, and smoothness of the surface, as well as a lower thickness. This research study aimed to develop self-levelling gypsum pastes (GSL), with only beta gypsum as a binder, as well as to evaluate the influence of the superplasticizer additive based on polycarboxylate (PCE). A dosage study was carried out on pastes containing a water-to-gypsum ratio of 0.35; 0.40; 0.45; $0.475 ; 0.50$, and 0.55 along with the superplasticizer additive content adjusted for self-levelling spreading. The pastes were characterized in the fresh state as to the setting times, spreading and heat of hydration time. In the hardened state for resistance to compression, traction in flexion, surface hardness and SEM. GSL pastes were obtained with a water-to-plaster ratio of 0.45 and 0.475 , containing 3.5 and $2.0 \%$ PCE, respectively. The PCE increased the setting times, modified the crystalline structure of the hemihydrate, and reduced the interlocking of the crystals with the consequent decrease in the mechanical properties.

Keywords: Gypsym. Self-levelling. Subfloor. Polycarboxylate. Microstructure. 


\section{Introdução}

O contrapiso convencional consiste em uma argamassa seca do tipo "farofa" à base de cimento Portland, cuja compactação é realizada manualmente e, após a execução, deve ser isolada do trânsito de pessoas e equipamentos por no mínimo dois dias (FIORITO, 2009). Nakakura e Bucher (1997) destaca que o contrapiso possui espessuras elevadas, apresenta baixa produtividade de execução e uma tendência ao aparecimento de manifestações patológicas como descolamentos, fissuração, ondulações e desníveis.

As argamassas autonivelantes, ou self-levelling mortar (SLM), configuram uma possibilidade para aumentar a produtividade na execução de contrapisos e são constituídas por aglomerantes cimentícios, agregados e aditivos (GEORGIN et al., 2008). Possuem elevada fluidez, alta deformabilidade e resistência à segregação, assim como o concreto autoadensável (YANG; ZHANG; YAN, 2016; LOPES DA SILVA, 2016). Destacam-se ainda pela rapidez na execução, redução do desperdício de material e economia com mão de obra (CARVALHO, 2015).

Uma forma alternativa de produzir um contrapiso autonivelante é empregando o sulfato de cálcio hemihidratado (gesso natural - $\mathrm{CaSO}_{4} \cdot 1 / 2 \mathrm{H}_{2} \mathrm{O}$ ) ou o fosfogesso, que é um gesso de origem química e possui propriedades físicas semelhantes às do gesso natural (CANUT, 2006). Até o momento, são inexistentes pesquisas científicas sobre o comportamento do contrapiso autonivelante apenas à base de gesso para a construção civil, que é o gesso beta. Na verdade, os estudos bibliográficos exploraram as propriedades do contrapiso autonivelante em sistemas contendo aglomerantes cimentícios (Portland, aluminato de cálcio, sulfoaluminato de cálcio) e hemi-hidratos, anidritas, fosfogessos ou fosfoanidritas.

Yang, Zhang e Yan (2016) investigaram argamassas autonivelantes contendo aglomerantes cimentícios, fosfogesso e superplastificante (0,4\%), que atenderam aos critérios das normas chinesas. Zhi et al. (2017) produziram pastas autonivelantes à base de fosfogesso de alta resistência e superplastificantes à base de policarboxilato (PCE), que alcançaram $350 \mathrm{~mm}$ de espalhamento e 54,25 $\mathrm{MPa}$ de resistência à compressão com $0,2 \%$ de aditivo PCE. Schaefer, Cheriaf e Rocha (2017) estudaram argamassas autonivelantes à base de cimento, fosfogesso, fosfoanidrita, gesso beta e PCE, que obtiveram fluidez maior que $250 \mathrm{~mm}$ e alcançaram a resistência à compressão de $9,20 \mathrm{MPa}$ e $24,80 \mathrm{MPa}$ com o emprego do gesso beta e fosfoanidrita, respectivamente.

Zhang et al. (2018) avaliaram argamassas autonivelantes contendo gesso alfa, anidrita, di-hidrato, cimento e PCE, e mostraram que o sulfato de cálcio mais adequado foi a anidrita, devido a apresentar a menor perda da fluidez, maiores tempos de pega e resistência à compressão de 45,0 $\mathrm{MPa}$ e à tração na flexão de 9,0 $\mathrm{MPa}$. Wang e Jia (2019) desenvolveram argamassas autonivelantes contendo cimento, fosfogesso e PCE, entre outros aditivos, que atenderam aos critérios normativos chineses com valores de resistência à compressão e à tração na flexão maiores do que 6,0 e 2,5 MPa, respectivamente, e diâmetros de espalhamento entre $140 \mathrm{~mm}$ e $150 \mathrm{~mm}$.

As pastas e argamassas autonivelantes contendo gesso, denominadas por Zhi et al. (2017) de GSL (gypsum based self-levelling mortar), apresentam pega rápida, baixa retração e podem ser aplicadas em grandes superfícies sem juntas de dilatação (SCHAEFER; CHERIAF; ROCHA, 2017). Zhi et al. (2017) apontam que o GSL proporciona melhor isolamento térmico e acústico, resistência ao fogo, conforto térmico, impede a formação de fissuras e proporciona uma redução de $20 \%$ na emissão de carbono e $60 \%$ no consumo de energia em comparação ao contrapiso autonivelante à base de cimento (CSL).

No entanto, o GSL não é indicado para ambientes em contato com água ou umidade devido à alta solubilidade do hemi-hidrato de cálcio e não pode ser empregado como a última camada do sistema de piso devido à baixa dureza superficial e, principalmente, à baixa resistência ao desgaste superficial. Pinho (2015) pontua que em função da alta fluidez, o contrapiso autonivelante não pode ser aplicado sobre superfícies inclinadas ou que precisem de caimento, além de ser necessário o fechamento de ralos, shafts e quaisquer aberturas que permitam a fuga do material.

Segundo Carvalho (2015), a obtenção da fluidez ideal das pastas poderia ser alcançada com o aumento do teor de água da composição, que implicaria a diminuição da resistência mecânica. Logo, são empregados aditivos para melhorar a fluidez do material sem aumentar o consumo de água (GAMA, 2017). Tan et al. (2018) apontam que o superplastificante à base de policarboxilato (PCE), que é um polímero polieletrólito (NEUVILLE et al., 2012), proporciona excelente dispersão tanto em materiais à base de cimento como gesso, podendo compor materiais autonivelantes.

Tem-se que no início da hidratação do hemi-hidrato os grupos aniônicos carboxila da cadeia principal do PCE são combinados de forma complexa com os íons $\mathrm{Ca}^{2+}$ presentes na superfície do hemi-hidrato, criando

312 Silva, D. B. P. da; Pontes, I. de O. C.; Rodrigues, M. T. J.; Lima, N. B. de; Póvoas, Y. V. 
pontos de adsorção em um processo chamado de "ancoragem", que formam uma camada com potencial elétrico negativo, resultando em uma força repulsiva eletrostática (PENG et al., 2005; ZHI et al., 2018). Em seguida, como o PCE possui uma estrutura molecular em formato de pente as longas cadeias laterais são estendidas sobre o solvente afastando as partículas do gesso e proporcionando um efeito de dispersão por meio de repulsão ou impedimento estérico (ZHI et al., 2017, 2018; TAN et al., 2018).

Logo, o PCE possui uma distribuição espacial na interface sólido-líquido que impede a aglomeração das partículas de gesso (Figura 1), sendo o efeito de repulsão estérica menos afetado pela rápida hidratação do hemi-hidrato do que a repulsão eletrostática e, assim, a dispersão se mantém por maiores períodos (PENG et al., 2005; PAN; WANG, 2011; TAN et al., 2018).

A NBR 16765 (ABNT, 2019a) define o contrapiso autonivelante de gesso como um material para construção contendo polímeros, cargas e aditivos, com capacidade de se autonivelar quando fluído, mas não existe um consenso na literatura sobre a proporção de gesso:agregado nem sobre os benefícios do agregado em argamassas de gesso (DIAS; CINCOTTO, 1995; DELGADO; PIRES SOBRINHO, 1997; JOHN; ANTUNES, 2002; CORREIA, 2016), visto que o agregado diminui a trabalhabilidade devido ao fato de provocar o aumento da absorção de água e ao efeito de nucleação destacado por John e Antunes (2002). Por outro lado, as pastas de gesso têm seu emprego consolidado em diversas aplicações na construção civil (PERES; BENACHOUR; SANTOS, 2008), como revestimentos (DE MILITO, 2007), placas para forro (SAVI, 2012) e blocos de fundição (SANTOS, 2017).

Nesse aspecto, o presente trabalho teve como objetivo desenvolver pastas autonivelantes de hemi-hidrato de cálcio para contrapiso (GSL), à base de gesso beta e aditivo PCE. Espera-se contribuir com o conhecimento do GSL e a influência do PCE nas propriedades físicas, mecânicas e microestruturais, visto que as informações da literatura são incipientes.

\section{Materiais e métodos de ensaio}

\section{Materiais}

\section{Hemi-hidrato (GB)}

$\mathrm{O}$ estudo utilizou um hemi-hidrato de cálcio beta $\left(\mathrm{CaSO}_{4} \cdot 1 / 2 \mathrm{H}_{2} \mathrm{O}\right)(\mathrm{GB})$ conhecido no mercado como gesso lento e empregado comumente em revestimentos. O GB foi proveniente do Pólo Gesseiro do Araripe (PE) e obtido em sacos de papel kraft de $40 \mathrm{~kg}$ de um mesmo lote. A caracterização do GB pode ser observada na Tabela 1.

Figura 1 - Modelo de dispersão e adsorção do PCE no hemi-hidrato

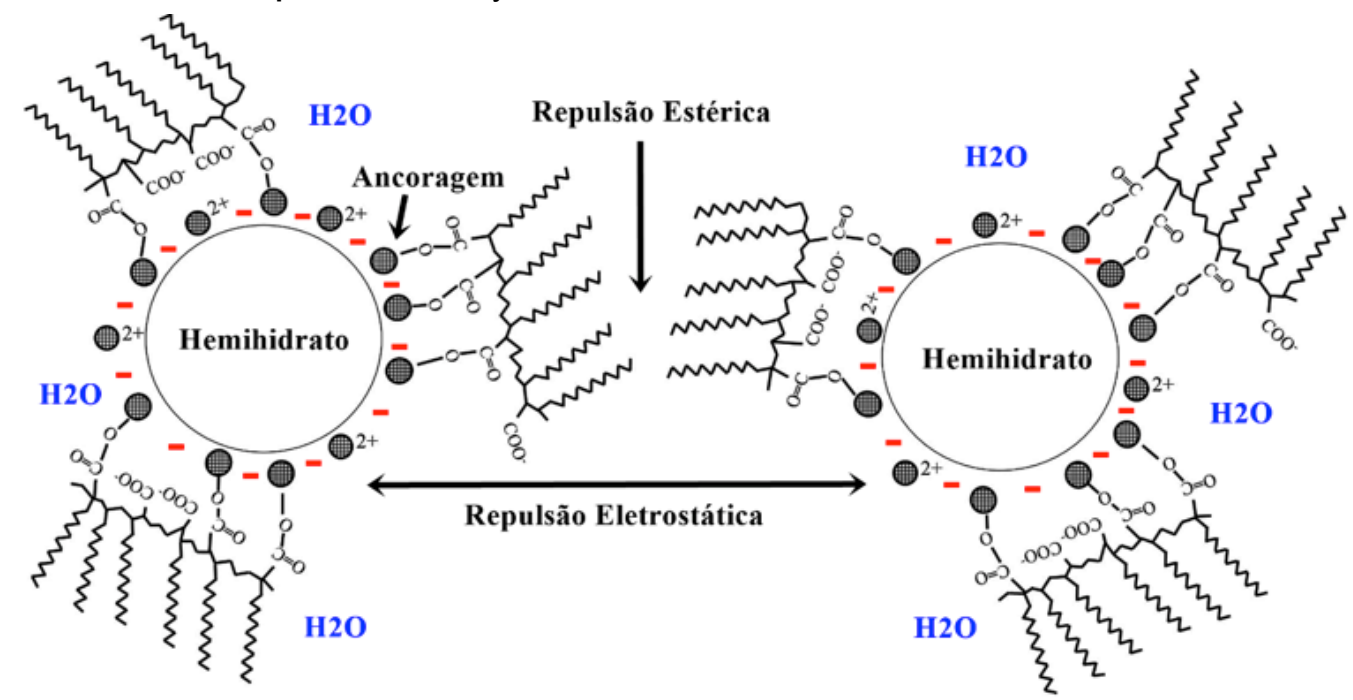

Fonte: adaptado de Zhi et al. (2018). 
Tabela 1 - Caracterização do GB em consistência normal (padrão)

\begin{tabular}{|c|c|c|c|}
\hline Propriedade & Valor & $\begin{array}{c}\text { Critério da NBR } 13207 \\
\text { (ABNT, 2017b) }\end{array}$ & Método de ensaio \\
\hline Água livre (\%) & $1,6 \pm 0,2$ & $<1,3$ & $\begin{array}{c}\text { NBR } 12130 \\
(\mathrm{ABNT}, 2019 \mathrm{~b})\end{array}$ \\
\hline Água de cristalização (\%) & $6,2 \pm 0,2$ & 4,2 a 6,2 & $\begin{array}{c}\text { NBR } 12130 \\
(\mathrm{ABNT}, 2019 \mathrm{~b})\end{array}$ \\
\hline Consistência normal (a/g) & 0,45 & - & $\begin{array}{c}\text { NBR } 12128 \\
(\mathrm{ABNT}, 2019 \mathrm{c})\end{array}$ \\
\hline Dureza superficial (N/mm ) & $62,84 \pm 1,17$ & $\geq 20,0$ & $\begin{array}{c}\text { NBR } 12129 \\
(\mathrm{ABNT}, 2019 \mathrm{~d})\end{array}$ \\
\hline Granulometria (\%) & $88,8 \pm 1,7$ & $\begin{array}{c}\geq 90 \% \text { (passante na peneira } \\
\text { de abertura } 0,21 \mathrm{~mm} \text { ) }\end{array}$ & $\begin{array}{c}\text { NBR } 12127 \\
(\mathrm{ABNT}, 2017 \mathrm{a})\end{array}$ \\
\hline Massa unitária (kg/m ) & $816,2 \pm 6,4$ & $\geq 600,0$ & $\begin{array}{c}\text { NBR 12127 } \\
(\mathrm{ABNT}, 2017 \mathrm{a})\end{array}$ \\
\hline Massa específica (g/cm ) & $2,41 \pm 0,04$ & - & $\begin{array}{c}\text { NBR NM } 23 \\
\text { (ASSOCIAÇÃO..., 2000) }\end{array}$ \\
\hline $\begin{array}{l}\text { Resistência à compressão } \\
(\mathrm{MPa})\end{array}$ & $20,7 \pm 0,6$ & $\geq 8^{1}$ & $\begin{array}{c}\text { NBR 13279 } \\
(\mathrm{ABNT}, 2005)\end{array}$ \\
\hline $\begin{array}{l}\text { Resistência à tração na } \\
\text { flexão }(\mathrm{MPa})\end{array}$ & $7,6 \pm 0,8$ & $\geq 3^{1}$ & $\begin{array}{c}\text { NBR } 13279 \\
(\mathrm{ABNT}, 2005)\end{array}$ \\
\hline $\begin{array}{l}\text { Tempo de início de pega } \\
\text { (min) }\end{array}$ & $11,3 \pm 0,4$ & $\geq 10$ & $\begin{array}{c}\text { NBR } 12128 \\
(\mathrm{ABNT}, 2019 \mathrm{c})\end{array}$ \\
\hline $\begin{array}{l}\text { Tempo de fim de pega } \\
\text { (min) }\end{array}$ & $18,3 \pm 0,4$ & $\geq 35$ & $\begin{array}{c}\text { NBR 12128 } \\
(\mathrm{ABNT}, 2019 \mathrm{c}) \\
\end{array}$ \\
\hline
\end{tabular}

Nota: ${ }^{1}$ requisito do projeto de norma PN 205:000.000-018 (ABNT, 2019e) para contrapiso autonivelante de gesso.

O GB possui uma água livre maior do que a tolerância definida na NBR 13207 (ABNT, 2017b), o que indica uma possível absorção de umidade do ambiente sem, no entanto, iniciar a hidratação devido ao fato de possuir água de cristalização dentro dos limites normativos. Possui granulometria maior do que o exigido, onde menos de $90 \%$ do material possui diâmetro menor do que $0,21 \mathrm{~mm}$. O material apresentou endurecimento mais rápido que o esperado para um gesso para revestimento, apresentando tempo de fim de pega menor do que $35 \mathrm{~min}$.

\section{Aditivo}

Aditivo superplastificante à base de policarboxilato (PCE) obtido no mercado local. Possui consistência líquida, densidade de $1,07 \pm 0,02 \mathrm{~kg} / \mathrm{l}$ e $\mathrm{pH}$ de $4,5 \pm 1,0$.

\section{Métodos de ensaio}

\section{Procedimento de mistura}

Procedimento definido na NBR 16765 (ABNT, 2019a) para o ensaio de espraiamento do GSL. Foi empregado um misturador mecânico de eixo planetário com velocidade lenta de 830 rpm e velocidade rápida de $1.680 \mathrm{rpm}$. Inicialmente, colocou-se na cuba (previamente seca), a água e o PCE e acionou-se o misturador por 30 segundos, em velocidade lenta. Em seguida, desligou-se o misturador e foi realizado o polvilhamento do hemi-hidrato de cálcio durante 1 minuto. Foi realizada a mistura por 30 segundos em velocidade baixa, desligando durante 15 segundos para retirar, com auxílio de uma espátula, a pasta aderida à parede da cuba e pá que não foi suficientemente misturada, colocando-a no interior da cuba. Por último, foi realizada a mistura por mais 15 segundos.

\section{Fluidez}

Teve como intuito definir a relação água/gesso (a/g) e o teor de PCE que proporcionassem ao GSL o diâmetro mínimo de $130 \mathrm{~mm}$ e propriedades físicas e mecânicas satisfatórias, segundo o projeto de norma PN 205:000.000-018 (ABNT, 2019e). Ressalta-se que os parâmetros apresentados no texto-base supracitado ainda estão em fase de análise e discussão, mas tiveram o seu emprego nesta pesquisa devido à carência de

314 Silva, D. B. P. da; Pontes, I. de O. C.; Rodrigues, M. T. J.; Lima, N. B. de; Póvoas, Y. V. 
informações consolidadas na literatura nacional e internacional. As relações a/g de 0,$35 ; 0,40 ; 0,45 ; 0,475$; 0,50 e 0,55 foram empregadas, sendo 0,45 a consistência normal do GB. O teor de PCE foi definido de forma exploratória para cada relação $\mathrm{a} / \mathrm{g}$ através do ensaio de espraiamento.

\section{Espraiamento}

Realizado conforme a NBR 16765 (ABNT, 2019a) para a obtenção do índice de espraiamento do GSL. Os equipamentos necessários foram: balança com resolução mínima de $0,1 \mathrm{~g}$, misturador mecânico, paquímetro, molde cilíndrico de PVC com $40 \mathrm{~mm}$ de diâmetro e $50 \mathrm{~mm}$ de altura, placa de vidro com dimensão de lado ou diâmetro mínimo de $30 \mathrm{~cm}$, nível de bolha para verificar o nivelamento da placa de vidro e espátula (Figura 2).

Inicialmente, foi realizada a limpeza da placa de vidro e do molde cilíndrico para a posterior pesagem e mistura dos materiais. Após a mistura das pastas, realizou-se o preenchimento do molde cilíndrico seguido do rasamento da superfície, eliminando qualquer sobra de material. $\mathrm{O}$ molde foi retirado verticalmente de maneira suave e após a estabilização do espraiamento foram realizadas 3 medidas do diâmetro do espalhamento da pasta com o auxílio de um paquímetro em pares de pontos uniformemente distribuídos (Figura 3). Após o registro das três medidas de espalhamento foi determinado o índice de espraiamento, que consiste na média das três medidas de diâmetro, expressa em milímetros e arredondada ao número inteiro mais próximo.

Foi realizada a análise visual qualitativa das condições de bordas classificando as pastas em uniformes, quando o espraiamento for circular, e desuniformes, quando for irregular (Figura 4). Também foram observadas a existência de exsudação e segregação nas pastas.

Figura 2 - Acessórios para o ensaio de espraiamento

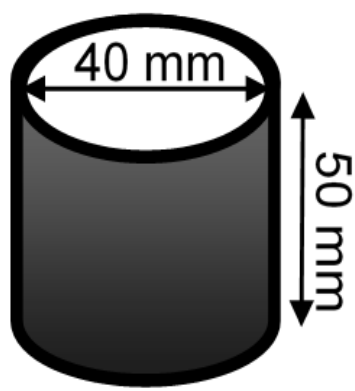

(a) Esquema do molde cilíndrico

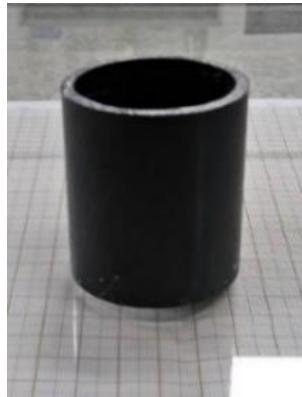

(b) Molde cilíndrico

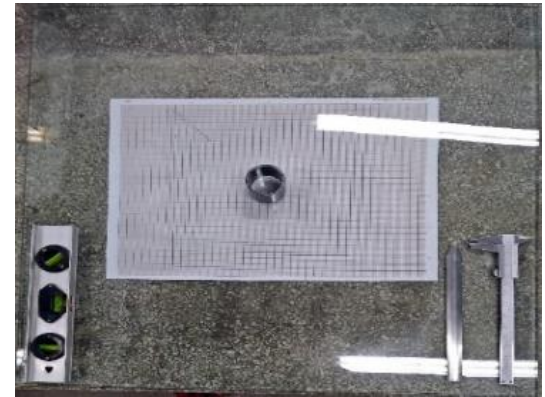

(c) Placa de vidro, nível de bolha, molde cilíndrico, paquímetro e espátula

Figura 3 - Leitura do espraiamento

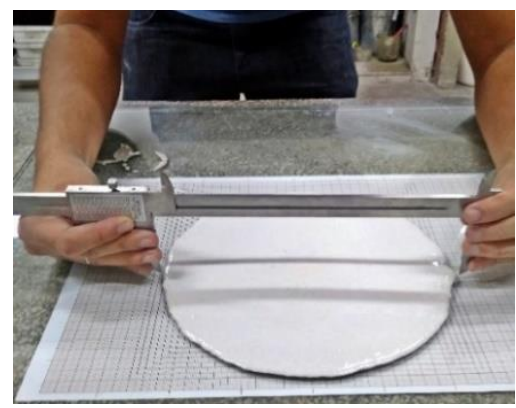


Figura 4 - Condições de borda do GSL

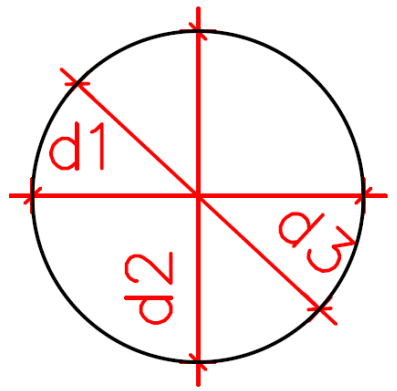

(a) Borda uniforme

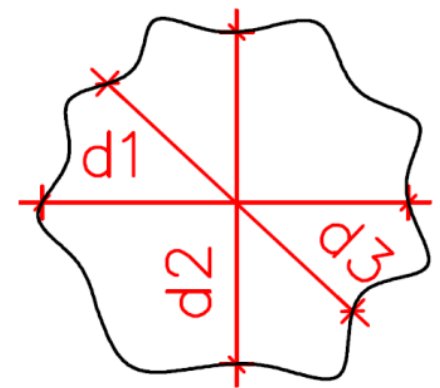

(b) Borda desuniforme

\section{Caracterização das pastas}

Após o ajuste do teor de PCE, para cada relação a/g, as pastas foram caracterizadas quanto ao tempo de pega e ao calor de hidratação. No estado endurecido quanto a resistência à compressão e à tração na flexão. As pastas que obtiveram as melhores propriedades físicas e mecânicas, de acordo com os critérios do PN 205:000.000-018 (ABNT, 2019e), foram caracterizadas quanto à dureza superficial e microestruturalmente, por meio do ensaio de microscopia eletrônica de varredura (MEV).

\section{Tempos de pega}

Realizado conforme a NBR 12128 (ABNT, 2019c) empregando o aparelho de Vicat. O início da pega do GSL se deu no instante em que a agulha do aparelho de Vicat permaneceu afastada $1 \mathrm{~mm}$ da base de vidro, no mínimo. O fim de pega foi determinado no instante em que a agulha não mais penetrou na pasta, deixando apenas uma leve impressão na superfície. Os resultados foram expressos por meio da média de, pelo menos, duas determinações com variação de até $5 \%$ entre elas.

\section{Calor de hidratação}

O ensaio de calor de hidratação, ou cinética de temperatura, tem o objetivo de avaliar a liberação de calor das pastas em função do tempo para a determinação das curvas de calor de hidratação e dos tempos de pega das pastas. Foi utilizado um equipamento em condições pseudoadiabáticas, semelhantemente ao utilizado por Pinheiro (2011) e Antunes (1999). Esse equipamento é constituído por um recipiente em formato de garrafa com tampa, de poliestireno (isopor) e, no interior, um copo plástico descartável que recebeu a pasta de gesso (Figura 5). Para aumentar o isolamento do material e reduzir a passagem do calor para o ambiente foi utilizado um material de baixa condutividade térmica, espuma de poliuretano, nos espaços vazios do calorímetro.

Para a coleta e gravação da temperatura das amostras foi utilizado um termômetro digital do tipo Minipa MT-1044, com função de datalogger, que possui quatro canais para conectar com os termopares de contato tipo $\mathrm{K}$, resolução de $0,1{ }^{\circ} \mathrm{C}$ e temperatura de operação entre $0{ }^{\circ} \mathrm{C}$ e $50{ }^{\circ} \mathrm{C}$. O termopar fica localizado na tampa do recipiente de isopor que ficará em contato com a pasta. Após a mistura as pastas foram inseridas no recipiente no interior do calorímetro. De forma automática o termômetro registrou a liberação de calor em intervalos de 5 segundos para a posterior confecção do gráfico da temperatura $\left({ }^{\circ} \mathrm{C}\right)$ versus tempo (min) e determinação dos tempos de pega e da atividade cinética.

\section{Resistência à compressão e à tração na flexão}

Realizados segundo a NBR 16765 (ABNT, 2019a), que indica a NBR 13279 (ABNT, 2005). Para cada pasta foi moldada uma série contendo três corpos de prova prismáticos de dimensões $(4 \times 4 \times 16) \mathrm{cm}$. Após o endurecimento, os corpos de prova foram desmoldados e submetidos à cura seca em estufa com temperatura entre $28^{\circ} \mathrm{C}$ e $45^{\circ} \mathrm{C}$, até a constância de massa, durante quatro dias. Em seguida, foram transferidos para o dessecador, onde permaneceram durante 24 horas com o intuito de alcançar a temperatura ambiente sem ganhar umidade. No sexto dia de idade, os corpos de prova foram ensaiados. Foi empregada uma prensa hidráulica do tipo Emic DL60000, célula de carga de $20 \mathrm{KN}$, velocidade de $50 \mathrm{~N} / \mathrm{s}$ para tração na flexão e $500 \mathrm{~N} / \mathrm{s}$ para compressão. Conforme a NBR 13279 (ABNT, 2005), foram usados os mesmos corpos de prova para a avaliação da resistência à tração na flexão e à compressão, assim como, não houve a necessidade de capeamento.

316 Silva, D. B. P. da; Pontes, I. de O. C.; Rodrigues, M. T. J.; Lima, N. B. de; Póvoas, Y. V. 


\section{Dureza superficial}

Realizado de acordo a NBR 12129 (ABNT, 2019d). Para cada pasta foi moldada uma série contendo três corpos de prova cúbicos de dimensões $(5 \times 5 \times 5) \mathrm{cm}$. O ensaio consistiu no contato de uma esfera de aço duro com 10,0 $\mathrm{mm}$ de diâmetro em três superfícies do corpo de prova por meio de uma prensa hidráulica Emic DL60000, célula de carga de $10 \mathrm{KN}$, que aplicou uma carga de $50 \mathrm{~N}$ e aumentou em 2 segundos para $500 \mathrm{~N}$, permanecendo por 15 segundos. Em seguida, foram feitas três medições da impressão da esfera na superfície dos corpos de prova, com o auxílio de um paquímetro digital, e seguiu-se para o cálculo da dureza superficial, em N/mm .

\section{Microscopia Eletrônica de Varredura (MEV)}

Foram moldadas três séries de corpos de prova cúbicos $(5 \times 5 \times 5) \mathrm{cm}$, uma referente à pasta $\mathrm{GB}$ e duas de GSL que apresentaram as melhores propriedades físicas e mecânicas, com cura e idades iguais às demais avaliações no estado endurecido. Após a avaliação mecânica, foram extraídas amostras da região central do corpo de prova e fixadas a um suporte circular por meio de uma fita de carbono microperfurada, em seguida submetidas à metalização em um no equipamento Cressongton Carbon Coater 108 carbon. A morfologia foi avaliada utilizando um microscópio eletrônico de varredura JEOL JSM 6460 (Figura 6).

\section{Resultados e discussões}

\section{Espraiamento}

Os teores de PCE obtidos para cada relação a/g de GSL, assim como as condições de borda e os espraiamentos, podem ser observados na Tabela 2.

\section{Figura 5 - Ensaio de calor de hidratação em condições pseudoadiabáticas}

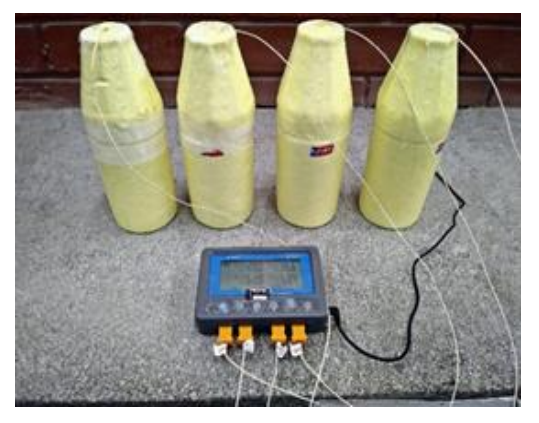

Figura 6 - Ensaio de microscopia eletrônica de varredura

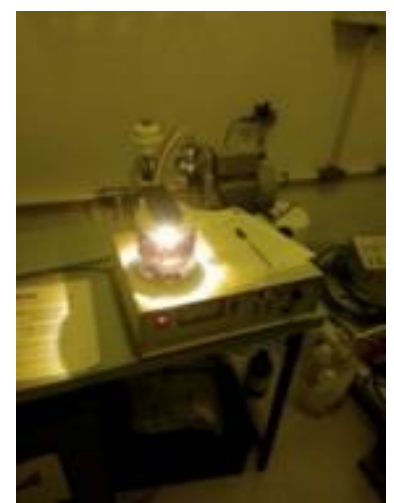

(a) Processo de metalização

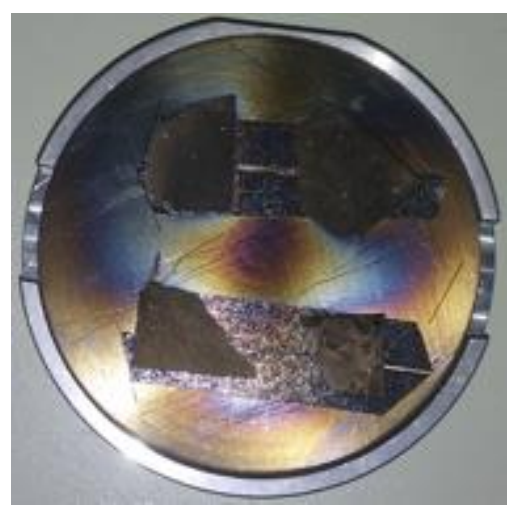

(b) Amostras prontas

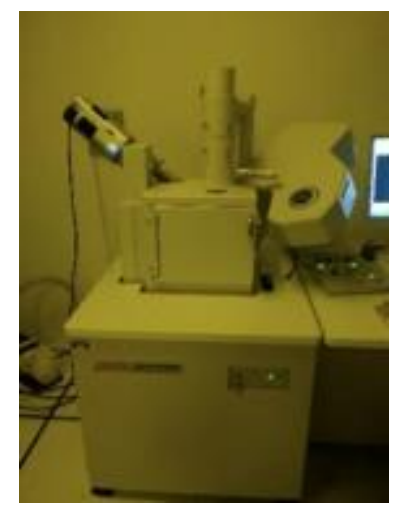

(c) Microscópio eletrônico de varredura 
Tabela 2 - Resultados do ensaio de espraiamento

\begin{tabular}{c|c|c|c|c|c|c|c|c|c}
\hline Pasta & $\mathbf{a} / \mathbf{g}$ & $\begin{array}{c}\text { PCE } \\
(\mathbf{\%})\end{array}$ & $\begin{array}{c}\text { Diâmetro } \\
(\mathbf{m m})\end{array}$ & Borda & Pasta & $\mathbf{a} / \mathbf{g}$ & $\begin{array}{c}\text { PCE } \\
(\boldsymbol{\%})\end{array}$ & $\begin{array}{c}\text { Diâmetro } \\
(\mathbf{m m})\end{array}$ & Borda \\
\hline $\mathbf{1}$ & 0,35 & 4,0 & 81,0 & $\mathrm{U}$ & $\mathbf{1 2}$ & 0,45 & 3,5 & 134,0 & $\mathrm{U}$ \\
\hline $\mathbf{2}$ & 0,35 & 5,0 & 87,0 & $\mathrm{U}$ & $\mathbf{1 3}$ & 0,45 & 3,0 & 128,0 & $\mathrm{D}$ \\
\hline $\mathbf{3}$ & 0,35 & 8,0 & 98,0 & $\mathrm{U}$ & $\mathbf{1 4}$ & 0,475 & 2,0 & 134,0 & $\mathrm{U}$ \\
\hline $\mathbf{4}$ & 0,35 & 10,0 & 104,0 & $\mathrm{U}$ & $\mathbf{1 5}$ & 0,50 & 1,00 & 142,0 & $\mathrm{U}$ \\
\hline $\mathbf{5}$ & 0,35 & 15,0 & 116,0 & $\mathrm{U}$ & $\mathbf{1 6}$ & 0,50 & 0,75 & 135,0 & $\mathrm{D}$ \\
\hline $\mathbf{6}$ & 0,35 & 20,0 & 128,0 & $\mathrm{D}$ & $\mathbf{1 7}$ & 0,50 & 0,50 & 130,0 & $\mathrm{U}$ \\
\hline $\mathbf{7}$ & 0,35 & 22,0 & 133,0 & $\mathrm{U}$ & $\mathbf{1 8}$ & 0,55 & 3,0 & 169,0 & $\mathrm{U}$ \\
\hline $\mathbf{8}$ & 0,40 & 10,0 & 124,0 & $\mathrm{U}$ & $\mathbf{1 9}$ & 0,55 & 2,0 & 165,7 & $\mathrm{U}$ \\
\hline $\mathbf{9}$ & 0,40 & 12,0 & 129,0 & $\mathrm{U}$ & $\mathbf{2 0}$ & 0,55 & 1,0 & 163,0 & $\mathrm{U}$ \\
\hline $\mathbf{1 0}$ & 0,40 & 13,0 & 132,0 & $\mathrm{U}$ & $\mathbf{2 1}$ & 0,55 & 0,5 & 143,0 & $\mathrm{U}$ \\
\hline $\mathbf{1 1}$ & 0,45 & 4,0 & 138,0 & $\mathrm{D}$ & $\mathbf{2 2}$ & 0,55 & 0,25 & 131,0 & $\mathrm{U}$ \\
\hline
\end{tabular}

Nota: Legenda:

$\mathrm{U}=$ uniforme;

$\mathrm{D}=$ desuniforme; $\mathrm{e}$

= pastas selecionadas.

O aumento no teor de PCE promoveu o crescimento da fluidez das pastas para todas as relações a/g. Segundo Zhi et al. (2018), o PCE, através de um processo de adsorção, aumenta a dispersão das pastas de gesso por meio de duas forças de repulsão distintas, eletrostática e estérica, que aumentam a distância entre as partículas de hemi-hidrato no momento da hidratação. Esse efeito dispersante do PCE proporciona uma maior quantidade de água livre e também a redução da tensão de escoamento, que ocasiona a diminuição da viscosidade e o consequente ganho de fluidez (ZHI et al., 2018).

Tendo em vista que o GSL necessita de uma fluidez com espraiamento mínimo de $130 \mathrm{~mm}$, foram necessárias 22 composições para definir o teor de PCE para cada relação a/g. As pastas $7(\mathrm{a} / \mathrm{g}=0,35), 10$ $(\mathrm{a} / \mathrm{g}=0,40), 12(\mathrm{a} / \mathrm{g}=0,45), 14(\mathrm{a} / \mathrm{g}=0,475), 17(\mathrm{a} / \mathrm{g}=0,50)$ e $22(\mathrm{a} / \mathrm{g}=0,55)$ (Figura 7) foram selecionadas e caracterizadas quanto aos tempos de pega, calor de hidratação, resistência à compressão e à tração na flexão.

As pastas de número $7,10,12,14,17$ e 22 necessitaram de $22 \%, 13 \%, 3,5 \%, 2,0 \%, 0,5 \%$ e 0,25\% de PCE, respectivamente. A análise visual indica que as pastas possuem bordas uniformes, sem segregação do material e nem exsudação. Os grumos presentes nas pastas 7, 10, 12 e 14 são decorrentes do final do material escoado do tubo de PVC no momento do ensaio de espraiamento.

A diminuição dos teores de PCE, com o crescimento da relação a/g, está relacionada com as reações de hidratação do hemi-hidrato. Segundo Singh e Middendorf (2007), o hemi-hidrato se dissolve rapidamente quando em contato com a água, saturando a solução de íons $\mathrm{Ca}^{2}+\mathrm{e} \mathrm{SO}_{4}{ }^{2-}$, que precipitam, reagem e formam o di-hidrato por meio e um processo físico e mecânico. Antunes (1999) aponta que a relação a/g é o parâmetro que exerce maior influência sobre a cinética de reação de hidratação, onde o seu crescimento prolonga o período para saturar a solução e, dessa forma, a pasta permanece fluida por mais tempo.

Karni e Karni (1995) apontam que o aumento da relação a/g faz crescer as distâncias entre as partículas proporcionando maior espaço para o crescimento dos cristais. Visto que o PCE possui efeito dispersante, com mecanismo explicado anteriormente, existirá um equilibro entre o seu teor e a relação $\mathrm{a} / \mathrm{g}$ da solução que proporcione a fluidez adequada e propriedades mecânicas satisfatórias ao GSL. Dessa forma, devido à baixa relação a/g da pasta 7 , houve a rápida hidratação do hemi-hidrato que consumiu a água livre fazendose necessário maiores quantidades de PCE para garantir a dispersão adequada (TAN et al., 2018). Por outro lado, na pasta 22 , que possui a maior relação a/g $(0,55)$, apenas $0,25 \%$ de PCE foi empregado devido às partículas de hemi-hidrato estarem mais afastadas.

Embora o processo de adsorção química e o mecanismo de dispersão do PCE sejam os mesmos no gesso e no cimento (TAN et al., 2018), a rápida reação de hidratação e endurecimento do hemi-hidrato faz com que perca fluidez muito rapidamente. Ou seja, para que pastas distintas de gesso e cimento nas mesmas condições de trabalhabilidade, que não refletem na mesma proporção de água, adquiriram a fluidez de autonivelamento o teor de PCE será maior nas pastas com o hemi-hidrato. Logo, a depender da trabalhabilidade da pasta de hemi-hidrato tomada como ponto de partida, o teor de PCE será maior ou menor.

318 Silva, D. B. P. da; Pontes, I. de O. C.; Rodrigues, M. T. J.; Lima, N. B. de; Póvoas, Y. V. 
Figura 7 - Espraiamento das pastas com teor de PCE ajustado

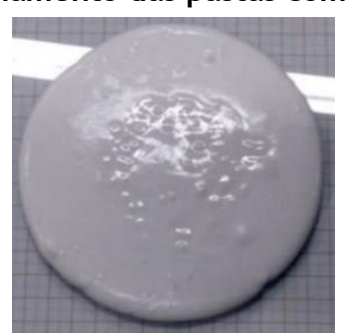

Pasta 7

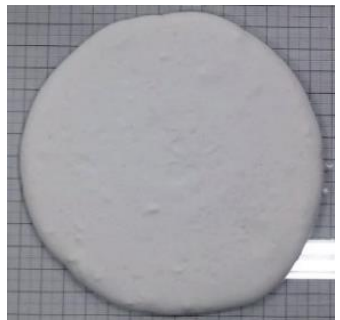

Pasta 14

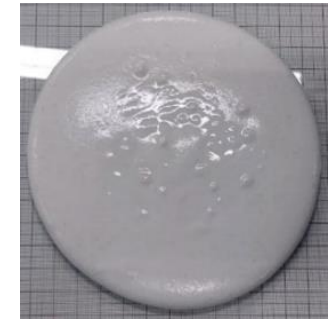

Pasta 10

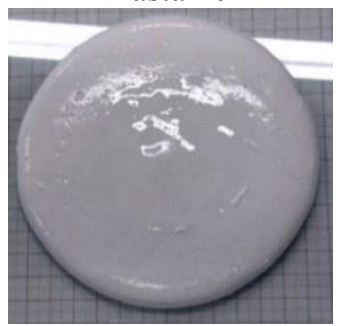

Pasta 17

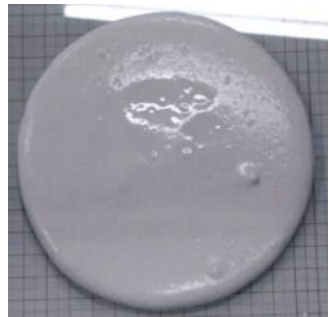

Pasta 12

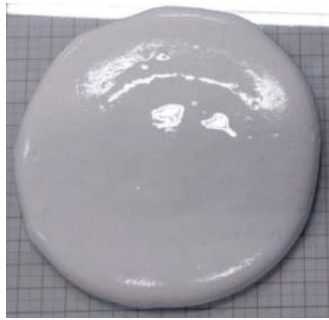

Pasta 22

A análise das pastas que alcançaram a fluidez de autonivelamento indica que o teor de PCE naquelas com relação $\mathrm{a} / \mathrm{g}$ menor que a consistência normal $(\mathrm{a} / \mathrm{g}=0,45)$, que foi utilizada na pasta 12 , foi demasiado e justifica-se pela pequena distância entre as partículas do hemi-hidrato que, ao entrarem em contato com a água, proporcionariam reações de hidratação e endurecimento do hemi-hidrato de forma instantânea sem a aplicação do PCE. Por outro lado, o incremento de água a partir de a/g=0,45 promove a dispersão do material que aumenta conforme cresce a proporção de água no sistema, retardando a hidratação.

Ou seja, o efeito único da relação a/g maior do que a consistência normal proporciona ganhos de fluidez que dispensam teores elevados de PCE. Tendo em vista os efeitos negativos sobre as propriedades mecânicas provocados por altas relações a/g (KARNI; KARNI, 1995), deverá ser determinada a proporção equilibrada de água e teor de PCE do GSL de forma a minimizar esses efeitos.

\section{Tempos de pega}

Os tempos de pega das pastas autonivelantes selecionadas, com teor de PCE ajustado para o espraiamento mínimo, e os critérios mínimos podem ser observados na Figura 8.

O emprego do PCE modificou as reações de hidratação das pastas que tiveram os tempos de pega retardados em relação à pasta GB. Esse efeito foi evidenciado nos estudos de Pan e Wang (2011) e Pinheiro (2011), nos quais o emprego de 1,0 e $1,5 \%$ de PCE aumentou o tempo de início da pega em 133\% e 360\%, respectivamente. Já na pasta 22 , que possui o menor teor de PCE $(0,25 \%)$, o tempo de início da pega foi retardado em 136\%; no entanto, a trabalhabilidade das pastas sem o PCE, assim como o tipo de hemi-hidrato empregado nesses estudos, deverá ser considerada para avaliar a eficiência do aditivo.

O PCE promove a redução na velocidade de hidratação e o aumento dos tempos de pega devido à adsorção química do PCE, que dispensa a utilização de outros componentes químicos retardadores dos tempos de pega. Pinheiro (2011) aponta que o emprego do PCE diminui a dissolução do hemi-hidrato, ampliando o período de indução, reduzindo a velocidade de formação dos pontos de nucleação e de crescimento dos cristais, resultando no maior tempo de endurecimento das pastas.

A não necessidade de um aditivo retardador dos tempos de pega simplifica a dosagem do GSL e impede que ocorra o efeito da adsorção competitiva (TAN et al., 2018; ZHI et al., 2018), quando um aditivo diminui a capacidade de adsorção do PCE que tem a propriedade dispersante reduzida, provocando o aumento na viscosidade e redução na fluidez da pasta. 
Figura 8 - Tempos de pega das pastas com teor de PCE ajustado

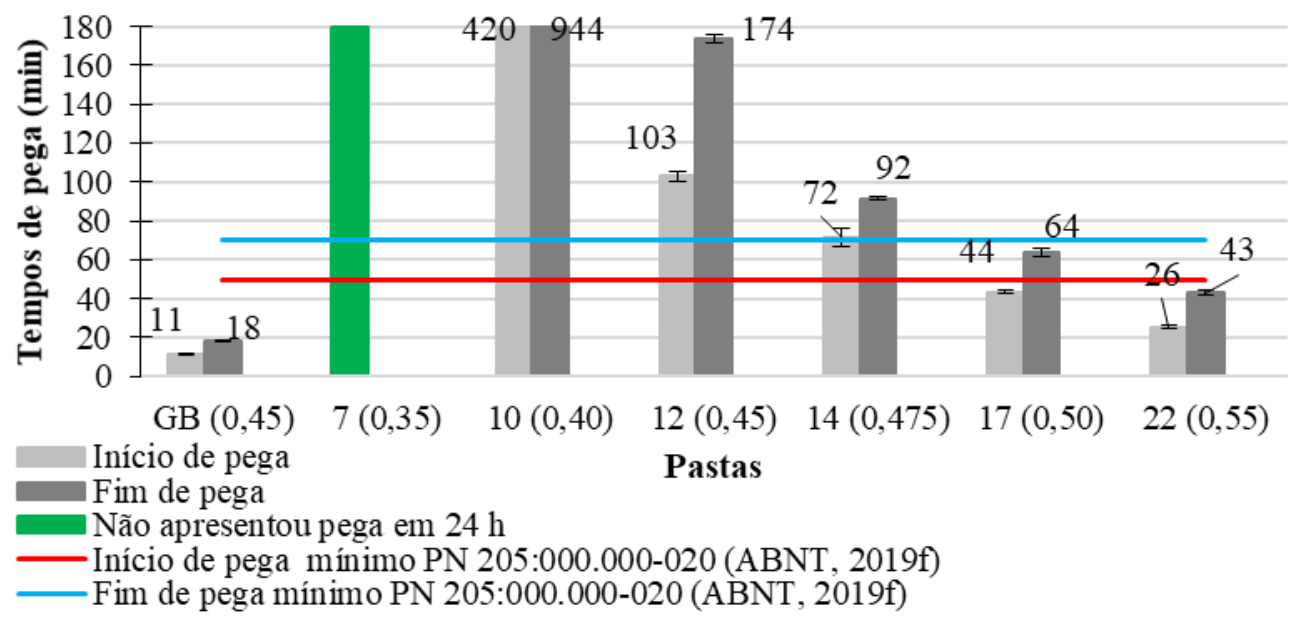

Conforme discutido na avaliação da fluidez das pastas, com o aumento da relação a/g o teor de PCE foi reduzido devido ao ganho de fluidez proporcionado pela água livre. Dessa forma, o efeito de repulsão eletrostática e de afastamento histérico causado pelo PCE foi diminuído, assim como a distância entre as partículas de hemi-hidrato, que aceleraram o processo de hidratação e diminuíram os tempos de pega. Ressalta-se que em pastas de gesso sem PCE o aumento da relação a/g é acompanhado pelo prolongamento dos tempos de indução, visto que a hidratação está sendo influenciada apenas pela água presente no sistema que afasta as partículas de hemi-hidrato (BARDELLA, 2011).

O PN 205:000.000-020 (ABNT, 2019f), que trata sobre o procedimento de execução do contrapiso autonivelante de gesso, determina que o contrapiso autonivelante deverá estar endurecido em até 24 h após a aplicação do material para a posterior execução da camada de revestimento. Logo, a pasta 7, que contém $22 \%$ de PCE, será excluída das demais avaliações no estado endurecido. O projeto de norma que trata dos critérios do GSL, o PN 205:000.000-018 (ABNT, 2019e), determina que o tempo de início de pega deve ser maior que $50 \mathrm{~min}$ e o tempo de fim de pega maior do que $70 \mathrm{~min}$, onde foi atendido nas pastas 10,12 e 14 .

$\mathrm{O}$ aumento na relação $\mathrm{a} / \mathrm{g}$ também reduziu os tempos úteis das pastas, onde a pasta 10 , que possui maior tempo de pega, tem o maior tempo útil, com 524 min. As pastas 12, 14, 17 e 22 possuem tempos úteis menores e iguais a $71 \mathrm{~min}, 20 \mathrm{~min}, 20 \mathrm{~min}$ e $17 \mathrm{~min}$, respectivamente.

\section{Calor de hidratação}

Na Figura 9 podem ser observadas as curvas de calor de hidratação em condições pseudoadiabáticas das pastas com teor de PCE ajustado.

As curvas possuem formato característico da liberação de calor do hemi-hidrato, com formato sigmoide ou sigmoidal (HINCAPIÉ; CINCOTTO, 1997; SINGH; MIDDENDORF, 2007), onde é possível analisar o período de indução, de aceleração e de reação lenta do processo de hidratação e endurecimento (FERREIRA; SOUSA; CARNEIRO, 2019). Segundo Lewry e Williamson (1994), a calorimetria tem a vantagem de produzir dados continuamente que são sensíveis a pequenas mudanças na taxa de reação.

As reações de hidratação das pastas são do tipo exotérmica, devido ao fato de ter havido a liberação do calor durante o processo de hidratação, com exceção das pastas 7 e 10, em que o demasiado teor de PCE inibiu a liberação de calor. As características obtidas por meio das curvas de hidratação são observadas na Tabela 3.

Tem-se que com o aumento da relação a/g houve a diminuição da energia liberada. A pasta GB alcançou a maior temperatura indicando possuir a maior velocidade de hidratação. Embora a pasta 12 possua a mesma relação a/g de GB, o teor de 3,5\% de PCE provocou a redução da velocidade de hidratação com a consequente diminuição na liberação de calor.

320 Silva, D. B. P. da; Pontes, I. de O. C.; Rodrigues, M. T. J.; Lima, N. B. de; Póvoas, Y. V. 
Figura 9 - Curvas de calor de hidratação das pastas autonivelantes com teor de PCE ajustado

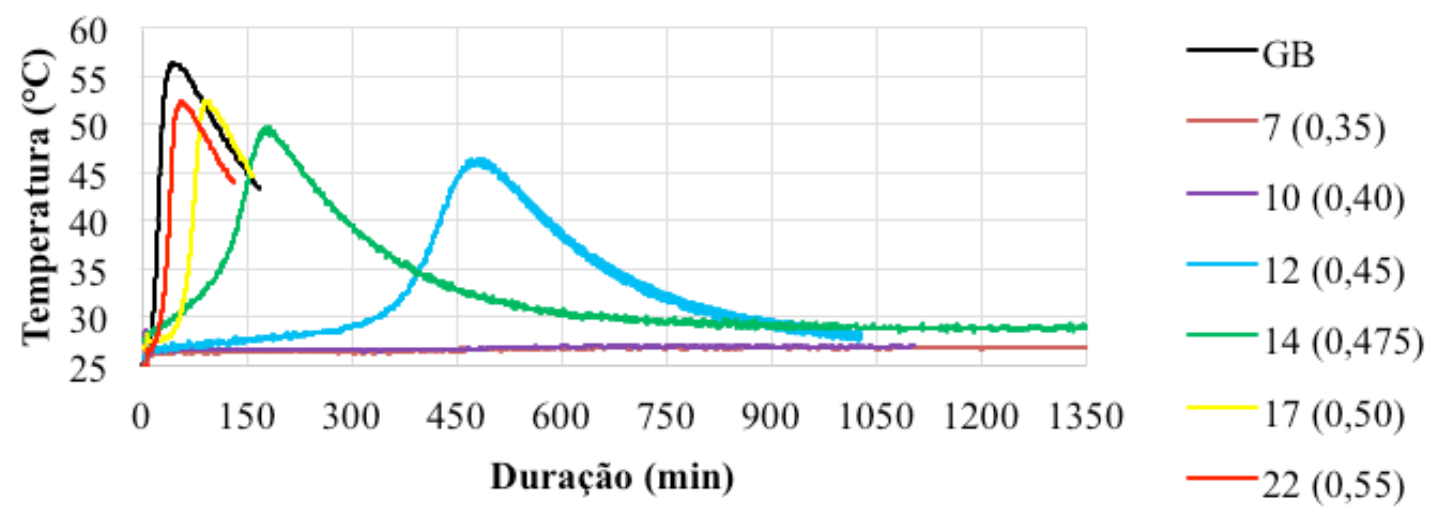

Tabela 3 - Caracterização das curvas de calor de hidratação do GSL

\begin{tabular}{l|c|c|c|c|c|c|c}
\hline \multicolumn{1}{c}{ Descrição } & & \multicolumn{7}{c}{ Pasta } \\
\cline { 2 - 8 } & $\mathbf{G B}$ & $\mathbf{7}$ & $\mathbf{1 0}$ & $\mathbf{1 2}$ & $\mathbf{1 4}$ & $\mathbf{1 7}$ & $\mathbf{2 2}$ \\
\hline Relação a/g & 0,45 & 0,35 & 0,40 & 0,45 & 0,48 & 0,50 & 0,55 \\
\hline Temperatura máxima $\left({ }^{\circ} \mathbf{C}\right)$ & 56,3 & - & - & 46,3 & 49,7 & 52,4 & 52,3 \\
\hline Tempo de fim da pega $(\mathbf{m i n})$ & 44,83 & - & - & 473,70 & 178,52 & 92,05 & 57,07 \\
\hline Atividade cinética $\left({ }^{\circ} \mathbf{C} / \mathbf{m i n}\right)$ & 0,698 & - & - & 0,045 & 0,133 & 0,276 & 0,461 \\
\hline
\end{tabular}

Um parâmetro importante para a avaliação da velocidade de hidratação é a atividade cinética, definida por Pinheiro (2011) como a razão entre a variação de temperatura (diferença entre a temperatura máxima e a inicial) e o tempo para alcançar a temperatura máxima, que coincide com o tempo de fim da pega. A pasta 12 possui atividade cinética 15 vezes menor que a pasta GB devido à adsorção química do PCE, além de ser a menor entre todas as pastas avaliadas, o que justifica o maior tempo para concluir a hidratação e o endurecimento. Com o aumento da relação $\mathrm{a} / \mathrm{g}$, e diminuição do PCE, a atividade cinética das pastas aumentou, mas todas são menores que a da pasta GB. Nas pastas 7 e 10 não foi possível calcular a atividade cinética devido ao fato de não apresentarem liberação de calor no período do ensaio.

As curvas de calor de hidratação corroboram os resultados de tempos de pega obtidos por meio do aparelho de Vicat: nas pastas com as menores relações a/g as curvas calorimétricas foram deslocadas para a direita, indicando o aumento do período de indução e o consequente retardo dos tempos de pega devido à adsorção química do PCE abordado anteriormente. Em pastas de hemi-hidrato puro as curvas são deslocadas para a direita com o aumento da relação a/g (PINHEIRO, 2011).

É possível estimar os tempos de pegas das pastas através das curvas calorimétricas e comparar com os valores obtidos através do aparelho de Vicat (FERREIRA; SOUSA; CARNEIRO, 2019). De acordo com Ridge (1959), o tempo de início da pega é caracterizado quando a taxa de elevação da temperatura (atividade cinética) ultrapassa $0,1{ }^{\circ} \mathrm{C} / \mathrm{min}$, indicando também o final do período de indução e início da etapa de aceleração. A etapa de aceleração é finalizada quando a pasta alcança a temperatura máxima, indicando o tempo de fim da pega e início da etapa de reação lenta ou endurecimento lento (ANTUNES, 1999).

Os tempos de pega obtidos através das curvas de hidratação e pelo Vicat podem ser observados na Tabela 4.

Os tempos de início, fim de pega e os tempos úteis obtidos através do calorímetro foram maiores que os obtidos pelo aparelho de Vicat. Ferreira, Sousa e Carneiro (2019), ao caracterizarem cinco pastas de gesso do Pólo Gesseiro do Araripe, verificaram que apenas o fim da pega, estimado pelas curvas calorimétricas, é maior que o obtido pelo método normativo que indica o aparelho de Vicat.

Embora a pasta 12 tenha endurecido, não foi possível determinar o tempo de início de pega através do calor de hidratação, visto que possui atividade cinética menor $0,1^{\circ} \mathrm{C} / \mathrm{min}$. Isso se deve à alteração na velocidade de hidratação causada pelo PCE que, devido à repulsão eletrostática e histérica, aumentou a distância das partículas de gesso levando à ampliação do período de indução (PENG et al., 2005; PAN; WANG, 2011; TAN et al., 2018). Assim, o crescimento lento dos cristais de di-hidrato proporciona o endurecimento das pastas de forma vagarosa, onde a taxa de liberação de calor não alcança o valor determinado por Ridge (1959). 
Tabela 4 - Tempos de pega obtidos pelo aparelho de Vicat e calorímetro

\begin{tabular}{c|c|c|c|c|c|c}
\hline \multirow{2}{*}{ Pasta } & \multicolumn{3}{|c|}{ Aparelho de Vicat } & \multicolumn{3}{c}{ Calorímetro } \\
\cline { 2 - 7 } & $\begin{array}{c}\text { Início da pega } \\
(\mathbf{m i n})\end{array}$ & $\begin{array}{c}\text { Fim da } \\
\text { pega (min) }\end{array}$ & $\begin{array}{c}\text { Tempo } \\
\text { útil (min) }\end{array}$ & $\begin{array}{c}\text { Início da } \\
\text { pega (min) }\end{array}$ & $\begin{array}{c}\text { Fim da } \\
\text { pega (min) }\end{array}$ & $\begin{array}{c}\text { Tempo } \\
\text { útil (min) }\end{array}$ \\
\hline GB & 11 & 18 & 7 & 8 & 45 & 37 \\
\hline $\mathbf{7}$ & - & - & - & - & - & - \\
\hline $\mathbf{1 0}$ & 420 & 944 & 524 & - & - & - \\
\hline $\mathbf{1 2}$ & 103 & 174 & 71 & - & 474 & - \\
\hline $\mathbf{1 4}$ & 72 & 92 & 20 & 142 & 179 & 36 \\
\hline $\mathbf{1 7}$ & 44 & 64 & 20 & 71 & 92 & 21 \\
\hline $\mathbf{2 2}$ & 26 & 43 & 17 & 30 & 57 & 27 \\
\hline
\end{tabular}

Obter os tempos de pega de pastas e argamassas através das curvas de calor de hidratação proporciona a avaliação da cinética química e das mudanças físicas sem a interferência do operador. Todavia, devem limitar-se aos sistemas sem aditivos redutores da atividade cinética, como o PCE ou aditivo retardador de pega, como o citrato de sódio. O aparelho de Vicat, que é recomendado para contrapiso autonivelante e pastas de gesso (ABNT, 2019a, 2019c), é mais suscetível a erros de operação e fornece dados apenas em função das mudanças físicas do gesso (BARDELLA, 2011), podendo, inclusive, fornecer falsos dados na avaliação dos tempos de pega de argamassas devido ao choque da agulha de Vicat com os agregados ou cargas.

\section{Resistência à compressão}

Na Figura 10 podem ser observados os valores obtidos de resistência à compressão das pastas com teor de PCE ajustado para autonivelamento.

O contrapiso é um material que poderá receber cargas de compressão que, dependendo da aplicação, poderá ser desde móveis e pessoas, até máquinas e equipamentos em uma fábrica. Não foi possível avaliar as propriedades mecânicas da pasta 7, com a/g de 0,35 , devido ao fato de não apresentar endurecimento após cinco dias do início da hidratação.

Todas as pastas obtiveram resistência à compressão menor que a pasta GB. Com o aumento da relação a/g houve o crescimento da resistência à compressão com exceção da pasta 22. Ao estudarem pastas de gesso sem aditivos John e Cincotto (2003), Kanno (2009) e Silva (2010) relataram a diminuição da resistência à compressão com o aumento da relação a/g devido ao aumento da porosidade que diminui o contato entre os cristais causando perda de resistência mecânica.

Pinheiro (2011) aponta que o aumento do período de indução com o emprego do PCE proporcionou a redução da resistência mecânica devido às mudanças na microestrutura. Esse efeito do PCE está associado à repulsão eletrostática e histérica que ao aumentarem as distâncias entre as partículas de gesso criam vazios na estrutura cristalina e modificam a morfologia e o entrelaçamento dos cristais (PAN; WANG, 2011), fatores apontados por Lewry e Williamson (1994) para a modificação da resistência.

Estudos realizados por Pan e Wang (2011) com gesso alfa indicaram que a adição de 0,3\% a 0,5\% de PCE melhora a resistência à compressão e à tração na flexão e reduz para os demais teores. Zhi et al. (2017) verificaram que a adição de $0,2 \%$ de PCE em pastas de fosfogesso alfa aumenta a resistência à compressão em 11,72\% devido à redução na geração de poros durante a hidratação tornando a estrutura mais compacta no estado endurecido.

Em relação ao critério mínimo de $8 \mathrm{MPa}$, considerando o desvio padrão dos valores obtidos, apenas a pasta 10 não atendeu ao critério, mesmo com a menor relação a/g e apresentou resistência $20 \%$ menor que a pasta de referência. Para a produção de um contrapiso autonivelante de gesso com PCE, as pastas deverão ter a maior quantidade de água que necessite do menor teor de PCE para alcançar o espraiamento mínimo e garanta as propriedades no estado fresco e endurecido satisfatórias.

\section{Resistência à tração na flexão}

$\mathrm{O}$ contrapiso atua como um elemento de placa que estará submetido às cargas que o farão flexionar. A NBR 16765 (ABNT, 2019a) recomenda a avaliação dessa propriedade no GSL, que segundo o PN 205:000.000-

322 Silva, D. B. P. da; Pontes, I. de O. C.; Rodrigues, M. T. J.; Lima, N. B. de; Póvoas, Y. V. 
18 (ABNT, 2019e) não deverá ter valor menor que $3 \mathrm{MPa}$. Os resultados de resistência à tração na flexão das pastas de gesso produzidas estão apresentados na Figura 11.

O comportamento da resistência à tração na flexão ocorreu semelhantemente ao observado na resistência à compressão. $\mathrm{O}$ aumento da relação $\mathrm{a} / \mathrm{g}$ até 0,50 proporcionou o crescimento da resistência de tração na flexão que alcançou 7,3 MPa. O aumento na quantidade de água fez as pastas necessitarem de menores teores de PCE, resultando na menor influência do aditivo nas propriedades mecânicas.

Tem-se que todas as pastas alcançaram valores médios menores que a pasta GB, visto que as altas propriedades mecânicas da pasta GB se devem à consistência normal, com relação a/g de 0,45 , e devido ao fato de não possuir aditivos. Porém, a pasta autonivelante 17 , com $50 \%$ de água e $0,50 \%$ de PCE, alcançou valor de resistência à tração na flexão estatisticamente igual à pasta $\mathrm{GB}$, com 7,3 $\mathrm{MPa}$. Em relação ao critério mínimo apenas a pasta 10, com relação a/g de 0,40 e 13\% de PCE, não atendeu ao critério.

\section{Dureza superficial}

Foi realizada a caracterização da dureza superficial das pastas que apresentaram os melhores resultados quanto aos critérios normativos para o contrapiso autonivelante de gesso, as pastas $12(\mathrm{a} / \mathrm{g}=0,45)$ e 14 $(\mathrm{a} / \mathrm{g}=0,475)$. Na Figura 12 podem ser observados os resultados de dureza superficial, em N/mm .

A dureza superficial foi reduzida em todas as pastas autonivelantes em relação à pasta GB, que obteve 62,8 $\mathrm{N} / \mathrm{mm}$. A pasta 12, pasta com relação a/g de 0,45 , obteve $24,7 \mathrm{~N} / \mathrm{mm}$, o menor valor de dureza superficial e $61 \%$ menor do que a pasta GB. Tem-se que houve o crescimento da dureza superficial com o aumento da relação a/g, assim como observado na resistência à compressão. Esse comportamento está relacionado com o teor de PCE, onde aumentando-se a proporção de água há a redução do teor de PCE e consequentemente a modificação da morfologia com a redução da porosidade dos cristais de di-hidrato devido à repulsão eletrostática e histérica do aditivo, semelhantemente ao ocorrido na resistência à compressão e à tração na flexão.

Figura 10 - Resistência à compressão das pastas autonivelantes com teor de PCE ajustado

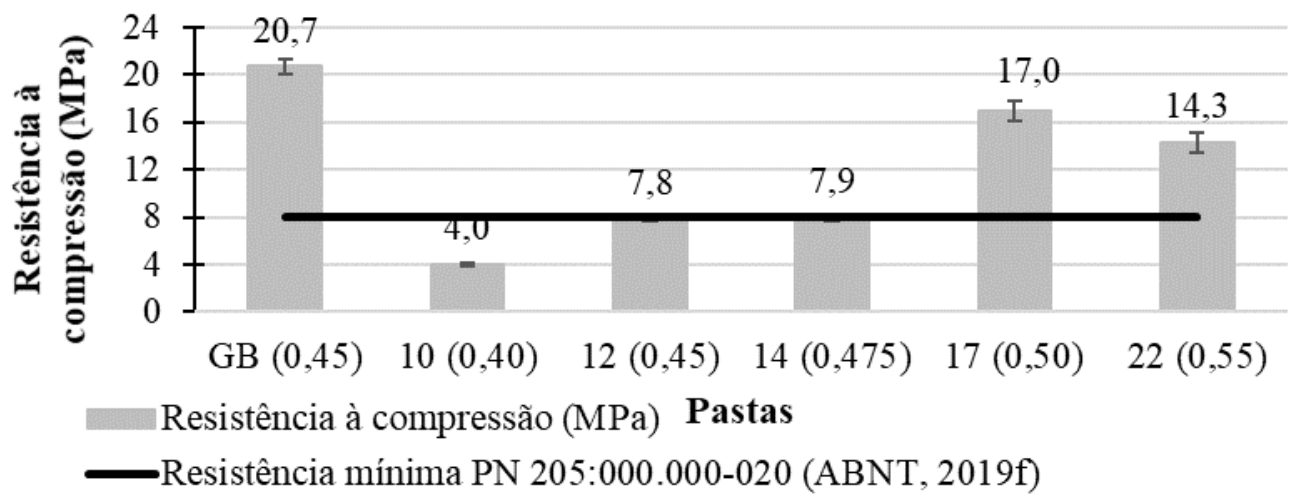

Figura 11 - Resistência à tração na flexão das pastas autonivelantes com teor de PCE ajustado

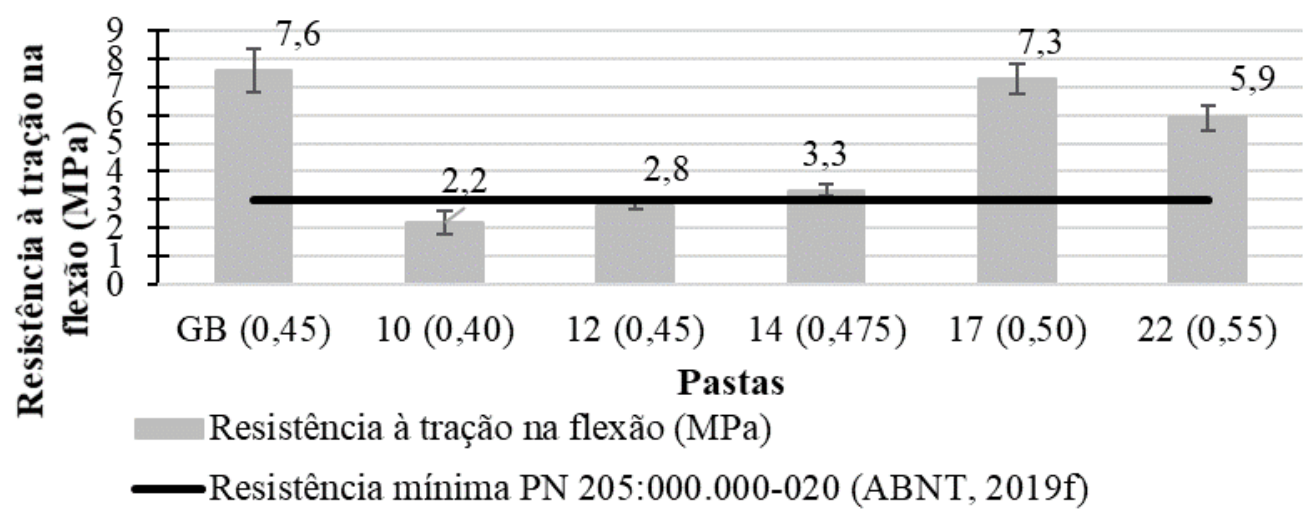


Figura 12 - Dureza superficial das pastas de melhor resultado

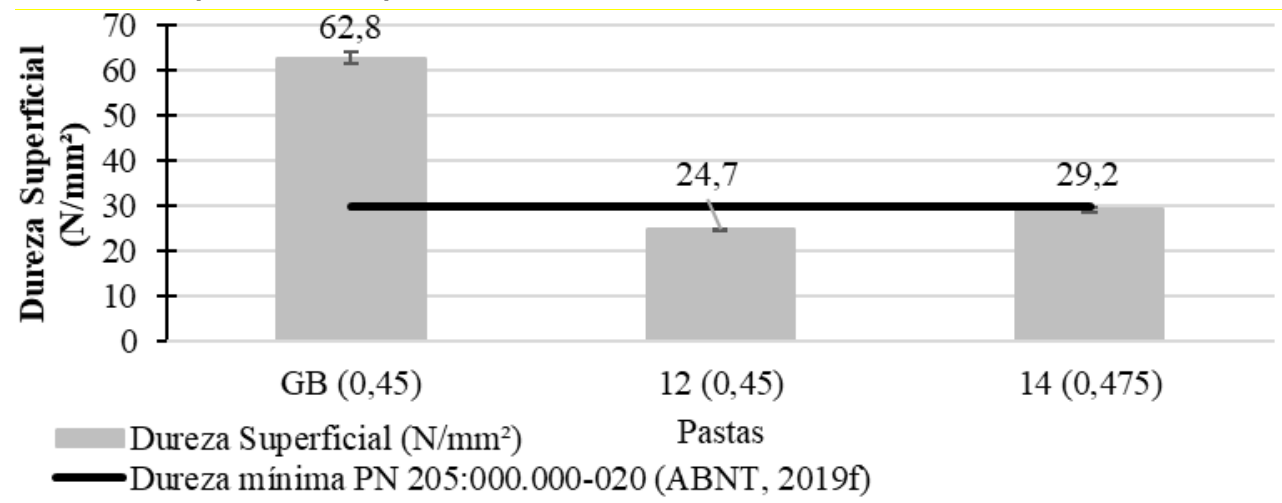

O projeto de norma PN 205:000.000-018 (ABNT, 2019) determina que a avaliação da dureza é opcional e não deverá ser menor do que $30 \mathrm{~N} / \mathrm{mm}$, que não foi alcançado nas pastas avaliadas. A não obrigatoriedade para a avaliação da dureza superficial deve-se ao fato de que a camada de contrapiso à base de gesso não pode ser a última camada do sistema de piso devido à baixa resistência ao desgaste por abrasão e à ação da água.

\section{Microscopia Eletrônica de Varredura (MEV)}

Realizado nas pastas de gesso beta (GB) e de GSL que apresentaram os melhores resultados segundo o projeto normativo, pastas $12(\mathrm{a} / \mathrm{g}=0,45)$ e $14(\mathrm{a} / \mathrm{g}=0,475)$. Na Figura 13 podem ser observadas as microscopias eletrônicas da pasta GB, com ampliação de 2.500 e 4.000 vezes, respectivamente.

A avaliação das micrografias indica que a pasta GB possui um arranjo cristalino composto por feixes (tufos) de cristais que cresceram de forma radial em torno do núcleo de cristalização durante o processo de endurecimento. Os cristais apresentam morfologia homogênea, bem definida, com hábito cristalino do tipo acicular, devido ao fato de os cristais possuírem forma de agulhas e serem pontiagudos, além da geometria alongada e fina, conforme também foi observado por Pinheiro (2011).

É possível avaliar a porosidade do material, de forma qualitativa, por meio dos vazios indicados pelas áreas escuras, onde Hincapié e Cincotto (1997) apontam que são resultantes da evaporação da água durante a secagem. Os cristais presentes na pasta GB estão agrupados em vários feixes que estão fortemente entrelaçados entre si (imbricados), semelhante ao observado por Pinheiro (2011) e Pinto (2014). Esse elevado grau de entrelaçamento justifica as elevadas propriedades mecânicas da pasta GB decorrente na baixa relação a/g (HINCAPIÉ; CINCOTTO, 1997).

$\mathrm{Na}$ Figura 14 podem ser observadas as micrografias eletrônicas da pasta autonivelante $12(\mathrm{a} / \mathrm{g}=0,45)$, com ampliações de 1.000 e 1.500 vezes, respectivamente.

Não foi possível obter micrografias das pastas 12 e 14 com ampliações maiores do que 1.500 vezes devido ao efeito de astigmatismo, que ocorre quando após o ajuste do foco a imagem fica esticada (MALISKA, 2020), dificultando ou impossibilitando as análises Não há evidências na literatura científica da relação do astigmatismo das micrografias com o PCE, que pode apresentar dificuldades de correção mesmo para operadores experientes (LU; ZHANG; LI, 2018). Pan e Wang (2011) avaliaram a micrografia do fosfogesso alfa com 1,0\% de PCE e ampliação de 2.000 vezes sem verificar esse efeito, assim como Pinheiro (2011), que aplicou estudou em pastas de gesso reciclado com 1,5\% de PCE e ampliações de 2.000 e 5.000 vezes. Porém, o tipo de hemi-hidrato e o teor de PCE podem ser fatores que contribuam para este defeito de leitura, visto que as pastas 12 e 14 possuem 3,5\% e 2,0\% de PCE, respectivamente, maiores do que os estudos citados.

A micrografia da pasta 12 (Figura 14) indica que o PCE modificou o arranjo cristalino e a morfologia dos cristais do di-hidrato em relação à pasta de GB, onde os cristais não estão agrupados e não possuem hábito cristalino definido. A análise morfológica indica que os cristais possuem geometria curta, grossa, pontiaguda e com alguns cristais em formato de placas sem entrelaçamento, semelhantemente ao observado por Pinheiro (2011). Segundo Lanzón e Garcia-Ruiz (2012), a redução no grau de intertravamento dos cristais reflete em menor desempenho mecânico, corroborando o menor desempenho da pasta 12 em relação à pasta GB.

324 Silva, D. B. P. da; Pontes, I. de O. C.; Rodrigues, M. T. J.; Lima, N. B. de; Póvoas, Y. V. 
Figura 13 - Micrografias da pasta GB com ampliação

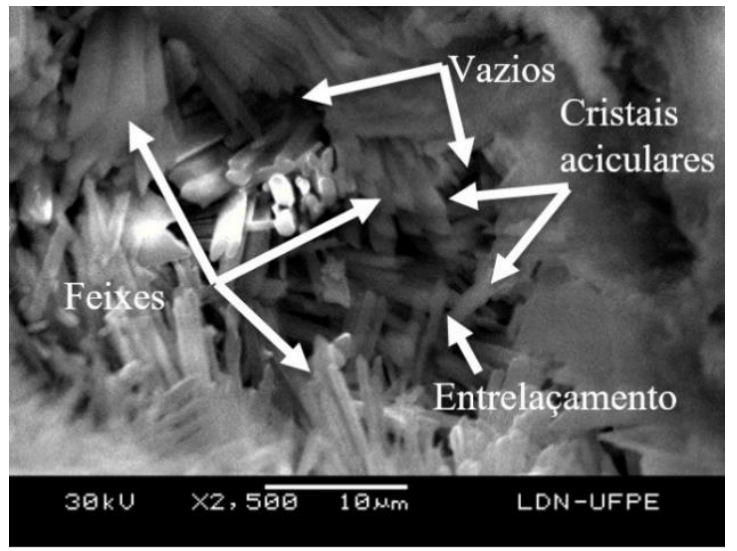

(a) 2.500 vezes

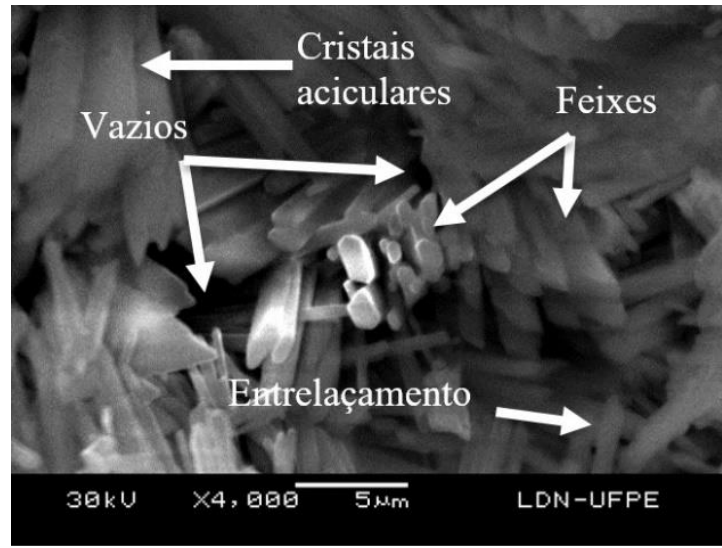

(b) 4.000 vezes

Figura 14 - Micrografias da pasta $12(\mathrm{a} / \mathrm{g}=0,45)$ com ampliação

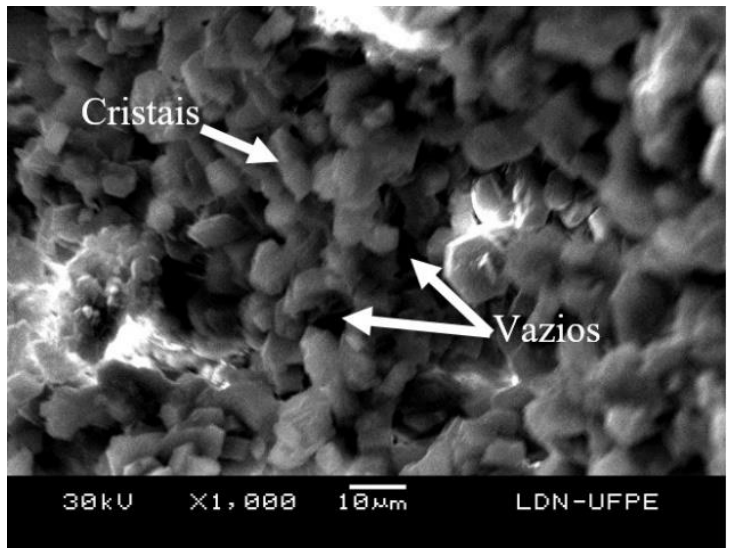

(a) 1.000 vezes

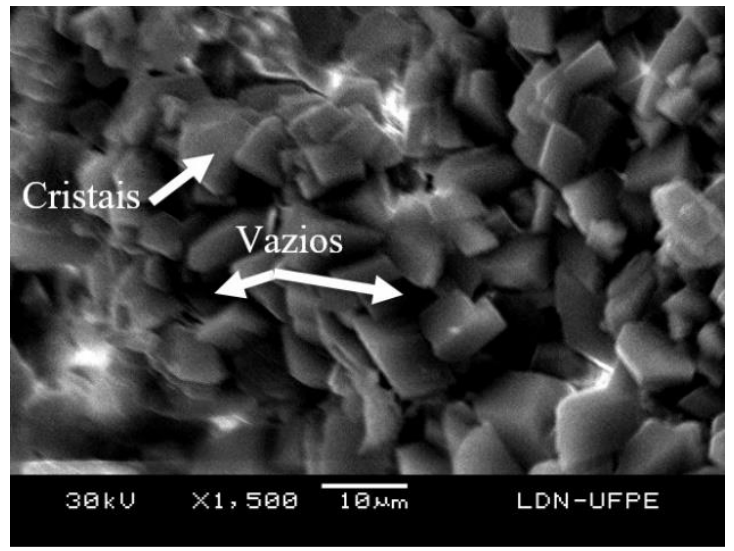

(b) 1.500 vezes

A modificação da estrutura cristalina está associada às mudanças na taxa de hidratação e ao aumento do tempo de indução devido à adsorção química do PCE na superfície dos cristais de hemi-hidrato (SINGH; MIDDENDORF, 2007; PINHEIRO, 2011), justificando a maior modificação da pasta 12, que possui maior tempo de pega que as pastas GB e 14, e menores propriedades mecânicas. Na Figura 15 podem ser observadas as micrografias eletrônicas da pasta autonivelante $14(\mathrm{a} / \mathrm{g}=0,475)$ com ampliações de $1.000 \mathrm{e}$ 1.500 vezes, respectivamente.

Os cristais da pasta 14 possuem geometria curta, não estão agrupados em feixes e estão sobrepostos sem apresentar hábito cristalino definido, semelhantemente ao observado na micrografia da pasta 12 (Figura 14). A redução no teor de PCE, devido ao aumento da relação a/g, ocasionou micrografias com cristais maiores e com pontas triangulares bem definidas, refletindo em ganho das propriedades mecânicas.

Segundo Pan e Wang (2011), quanto maior o tamanho do cristal melhor será a resistência à tração na flexão e cristais mais largos possuem melhor resistência à compressão, justificando a melhor resistência à tração na flexão da pasta 14 em relação a 12. No entanto, em relação à pasta GB, as pastas com o PCE tiveram a diminuição do entrelaçamento que ocasionou na redução da ligação intercristalina e das propriedades mecânicas. 
Figura 15 - Micrografia da pasta 14 (a/g=0,475), com ampliação de: (a) 1.000 e (b) 1.500 vezes

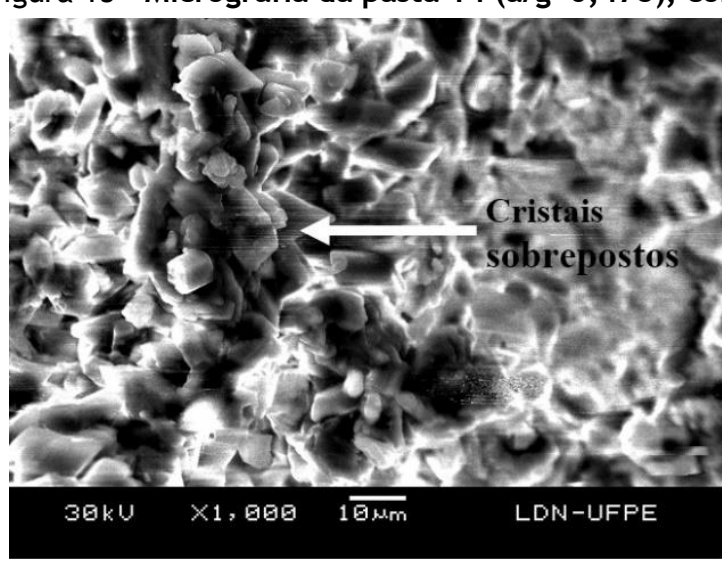

(a)

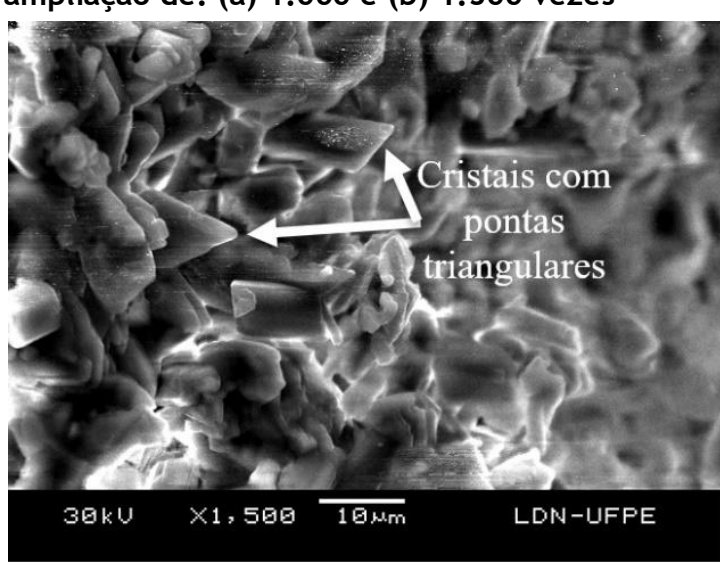

(b)

\section{Conclusão}

(a) as pastas de GSL à base de hemi-hidrato beta foram obtidas com o emprego de 3,5\% de PCE e relação $\mathrm{a} / \mathrm{g}$ de $0,45 \%$, e $2,0 \%$ de PCE e relação a/g de 0,475 ;

(b) a cinética química das pastas foi diminuída com a utilização do PCE, resultando em maiores tempos de pega; e

(c) o PCE proporcionou mudanças na morfologia dos cristais de hemi-hidrato e na redução do entrelaçamento, refletindo na diminuição da resistência à compressão e à tração na flexão.

\section{Referências}

ANTUNES, R. P. N. Estudo da influência da cal hidratada nas pastas de gesso. São Paulo, 1999. 145 f. Dissertação (Mestrado em Civil) - Escola Politécnica, Universidade de São Paulo, São Paulo, 1999.

ASSOCIAÇÃO BRASILEIRA DE NORMAS TÉCNICAS. NBR 12127: gesso para construção civil: determinação das propriedades físicas do pó. Rio de Janeiro, 2017a.

ASSOCIAÇÃO BRASILEIRA DE NORMAS TÉCNICAS. NBR 12128: gesso para construção civil: determinação das propriedades físicas da pasta de gesso. Rio de Janeiro, 2019c.

ASSOCIAÇÃO BRASILEIRA DE NORMAS TÉCNICAS. NBR 12129: gesso para construção civil: determinação das propriedades mecânicas. Rio de Janeiro, 2019d.

ASSOCIAÇÃO BRASILEIRA DE NORMAS TÉCNICAS. NBR 12130: gesso para construção civil: determinação da água livre e de cristalização e teores de óxido de cálcio e anidrido sulfúrico: método de ensaio. Rio de Janeiro, 2019b.

ASSOCIAÇÃO BRASILEIRA DE NORMAS TÉCNICAS. NBR 13207: gesso para construção civil: requisitos. Rio de Janeiro, 2017b.

ASSOCIAÇÃO BRASILEIRA DE NORMAS TÉCNICAS. NBR 13279: argamassa para assentamento e revestimento de paredes e tetos: determinação da resistência à tração na flexão e à compressão. Rio de Janeiro, 2005.

ASSOCIAÇÃO BRASILEIRA DE NORMAS TÉCNICAS. NBR 16765: contrapiso autonivelante de gesso: métodos de ensaio. Rio de Janeiro, 2019a.

ASSOCIAÇÃO BRASILEIRA DE NORMAS TÉCNICAS. PN 205:000.000-018: contrapiso autonivelante de gesso: requisitos. Rio de Janeiro, 2019e.

ASSOCIAÇÃO BRASILEIRA DE NORMAS TÉCNICAS. PN 205:000.000-020: contrapiso autonivelante de gesso: procedimento. Rio de Janeiro, 2019f.

ASSOCIAÇÃO MERCOSUL DE NORMALIZAÇÃO. NM 23: cimento Portland e outros materiais em pó: determinação da massa específica. Rio de Janeiro, 2000. 
BARDELLA, P. S. Análise das propriedades de pastas de gesso de construção reciclado. Campinas, 2011. 235 f. Tese (Doutorado em Engenharia Civil) - Faculdade de Engenharia Civil, Arquitetura e Urbanismo da Universidade Estadual de Campinas, 2011.

CANUT, M. M. C. Estudo da viabilidade do uso do resíduo fosfogesso como material de construção. 2006. 154f. Dissertação (Mestrado em Construção Civil) - Universidade Federal de Minas Gerais, Belo Horizonte, 2006.

CARVALHO, D. S. C. Análise da retração por secagem em argamassas autonivelantes utilizando adições minerais como substitutos parciais do Cimento Portland. 2015. 138f. Dissertação (Mestrado em Engenharia Civil) - Universidade Federal de Santa Catarina, Centro Tecnológico, Florianópolis, 2015.

CORREIA, D. C. A. Argamassas de terra para rebocos interiores: influência da adição de gesso e da granulometria da areia. 2016. 115 f. Dissertação (Mestrado em Engenharia Civil) - Faculdade de Ciência e Tecnologias da Universidade Nova de Lisboa, Lisboa.

DE MILITO, J. A. Avaliação do desempenho de aglomerante à base de gesso com cimento Portland de alto forno e sílica ativa. 2007. 365f. Tese (Doutorado em Engenharia Civil) - Universidade Estadual de Campinas, Campinas, 2007.

DELGADO, C. B.; PIRES SOBRINHO, C.W. A. Revestimentos de gesso (pasta e argamassa): determinação das propriedades mecânicas. In: SIMPÓSIO BRASILEIRO DE TECNOLOGIA DAS ARGAMASSAS, Salvador, 1997. Anais [...] Salvador, 1997.

DIAS, A. M. N; CINCOTTO, M. A. Revestimento à base de gesso de construção. Boletim técnico PCC, v. $142,1995$.

FERREIRA, F. C.; SOUSA, J. G. G.; CARNEIRO, A. M. P. Caracterização mecânica do gesso para revestimento produzido no Polo Gesseiro do Araripe. Ambiente Construído, Porto Alegre, v. 19, n. 4, p. 207-221, out./dez. 2019.

FIORITO, Antônio J. S. I. Manual de argamassas e revestimentos: estudos e procedimentos de execução. São Paulo: Pini, 2009.

GAMA, H. M. Desenvolvimento de contrapiso autonivelante com adição de metacaulim, aditivo polifuncional e aditivo modificador de viscosidade. Aracaju, 2017. $84 \mathrm{f}$. Trabalho de Conclusão de Curso (Graduação em Engenharia Civil) - Instituto Federal de Sergipe, Aracaju, 2017.

GEORGIN, J. F. et al. Development of self-leveling screed based on calcium sulfoaluminate cement: modelling of curling due to drying. Cement \& Concrete Composites, v. 30, p. 769-778, 2008.

HINCAPIE, A. M; CINCOTTO, M. A. Efeito de retardadores de pega no mecanismo de hidratação e na microestrutura do gesso de construção. Ambiente Construído, Porto Alegre, v. 1, n. 2, p. 7-16, abr./jun. 1997.

JOHN, V. M.; ANTUNES, R. P. N. Argamassas de gesso. Ambiente Construído, Porto Alegre, v. 2, n. 1, p. 29-37, jan./mar. 2002.

JOHN, V. M.; CINCOTTO, M. A. Alternativas de gestão dos resíduos de gesso: contribuição para Reformulação da Resolução CONAMA 307. São Paulo, 2003.

KANNO, W. M. Propriedades mecânicas do gesso de alto desempenho. São Carlos, 2009. 130 f. Tese (Doutorado em Ciências e Engenharia de Materiais) - Universidade de São Paulo, São Carlos, 2009.

KARNI, J.; KARNI, E. Y. Gypsum in construction: origin and properties. Materials and Structures, v. 28, n. 2, p. 92-100, 1995.

LANZÓN, M.; GARCÍA-RUIZ, P. A. Effect of citric acid on setting inhibition and mechanical properties of gypsum building plasters. Construction and Building Materials, v. 28, n. 1, p. 506-511, 2012.

LEWRY, A. J.; WILLIAMSON, J. The setting of gypsum plaster. Journal of materials science, v. 29, n. 23, p. 6085-6090, 1994.

LOPES DA SILVA, S. H. Desenvolvimento de pastas de argamassas autonivelantes para pisos e avaliação da retração por secagem. Curitiba, 2016. 117 f. Dissertação (Mestrado em Engenharia Civil) Programa de Pós-Graduação em Construção Civil, Universidade Federal do Paraná, Setor de Tecnologia, Curitiba, 2016. 
LU, Y.; ZHANG, X; LI, H. A simplified focusing and astigmatism correction method for a scanning electron microscope. AIP Advances, v. 8, n. 1, p. 015124, 2018.

MALISKA, A. M. Microscopia eletrônica de varredura. Florianópolis: Laboratório de Caracterização Microestrutural e Análise de Imagens - UFSC. Disponível em: http://www.usp.br/nanobiodev/wpcontent/uploads/MEV_Apostila.pdf. Acesso em: 15 jan. 2020.

NAKAKURA, E. H.; BUCHER, H. R. E. Pisos autonivelantes: propriedades e instalação. In: SIMPÓSIO BRASILEIRO DE TECNOLOGIA DAS ARGAMASSA, 2., Salvador, 1997. Anais [...] Disponível em: http://www.dcc.ufpr.br/mediawiki/images/8/80/TC034_Argamassa_auto_nivelante.pdf. Acesso em: 25 out. 2019.

NEUVILLE, M. et al. Rheology of a gypsum suspension in the presence of different superplasticizers. Journal of rheology, v. 56, n. 2, p. 435-451, 2012.

PAN, W.; WANG, P. Effect of compounding of sodium tripolyphosphate and super plasticizers on the hydration of $\alpha$-calcium sulfate hemihydrate. Journal of Wuhan University of Technology, Materials Science Edition, v. 26, n. 4, p. 737-744, 2011.

PENG, J. et al. Adsorption characteristics of water-reducing agents on gypsum surface and its effect on the rheology of gypsum plaster. Cement and Concrete Research, v. 35, n. 3, p. 527-531, 2005.

PERES, L.; BENACHOUR, M.; SANTOS, V. A. Gesso: produção e utilização na construção civil. Recife: SEBRAE, 2008.

PINHEIRO, S. M. M. Gesso reciclado: avaliação das propriedades para uso em componentes. Campinas, 2011. 329 f. Tese (Doutorado em Engenharia Civil) - Universidade Estadual de Campinas, Campinas, 2011.

PINHO, G. M. Viabilidade econômica do uso da argamassa autonivelante para contrapiso. Revista Especialize On-line IPOG, Goiânia, v. 1, n. 10, 2015.

PINTO, M. C. C. Avaliação das propriedades do gesso reciclado contendo aditivos. Campinas, 2014. 114 f. Dissertação (Mestrado em Engenharia Civil) - Universidade Estadual de Campinas, Programa de PósGraduação em Engenharia Civil, Campinas, 2014.

RIDGE, M. J. Effect of temperature on the rate of setting of gypsum plaster. Nature, v. 184, n. 4679, p. 4748, 1959.

SANTOS, A. N. Comportamento higrotérmico de paredes em gesso: avaliação da adequabilidade a zonas climáticas do Brasil. Porto, 2017. 210 f. Tese (Doutorado em Engenharia Civil) - Faculdade de Engenharia, Universidade do Porto, Porto, 2017.

SAVI, O. Produção de placas de forro com a reciclagem de gesso. Maringá, 2012. 231 f. Dissertação (Mestrado em Engenharia Civil) - Programa de Pós-Graduação em Engenharia Urbana, Universidade Estadual de Maringá, Maringá, 2012.

SCHAEFER, C. O.; CHERIAF, M.; ROCHA, J. C. Production of synthetic phosphoanhydrite and its use as a binder in Self-Leveling Underlayments (SLU). Materials, v. 10, n. 8, 2017.

SILVA, M. G. S. Desenvolvimento de compósitos à base de gesso e pó de fibras de coco. $84 \mathrm{f}$. São Cristovão, 2010. Dissertação (Mestrado em Engenharia Civil) - Escola de Engenharia, Universidade Federal de Sergipe, São Cristovão, 2010.

SINGH, N. B.; MIDDENDORF, B. Calcium sulphate hemihydrate hydration leading to gypsum crystallization. Progress in Crystal Growth and Characterization of Materials, v. 53, p. 57-77, 2007.

TAN, H. et al. Effect of borax and sodium tripolyphosphate on fluidity of gypsum paste plasticized by polycarboxylate superplasticizer. Construction and Building Materials, v. 176, p. 394-402, 2018.

WANG, Q.; JIA, R. A novel gypsum-based self-leveling mortar produced by Phosphorus building gypsum. Construction and Building Materials, v. 226, p 11-20, 2019.

YANG, L.; ZHANG, Y.; YAN, Y. Utilization of original phosphogypsum as raw material for the preparation of self-leveling mortar. Journal of Cleaner Production, v. 127, p. 204-213, 2016.

ZHANG, S. et al. Effect of calcium sulfate type and dosage on properties of calcium aluminate cementbased self-leveling mortar. Construction and Building Materials, v. 167, p. 253-262, 2018. 
ZHI, Z. et al. Effect of chemical admixtures on setting time, fluidity and mechanical properties of phosphorus gypsum based self-leveling mortar. KSCE Journal of Civil Engineering, v. 21, n. 5, p. 1836$1843,2017$.

ZHI, Z. et al. Effect of competitive adsorption between polycarboxylate superplasticizer and hydroxypropylmethyl cellulose on rheology of gypsum paste. Journal of Materials in Civil Engineering, v. 30, n. 7, 2018.

Daniel Bruno Pinto da Silva

Escola Politécnica de Pernambuco | Universidade de Pernambuco | Rua Benfica, 455, Madalena | Recife - PE - Brasil | CEP 50720-001 | Tel.: (81) 98857-4490 | E-mail: danielbruno.silva@hotmail.com

Izabelle de Oliveira Cardoso Pontes

Escola Politécnica de Pernambuco | Universidade de Pernambuco | Tel.: (81) 99746-6141 | E-mail: izabelleoliveira1@gmail.com

Mariana Tavares Jorge Rodrigues

Escola Politécnica de Pernambuco | Universidade de Pernambuco | Tel.: (81) 99662-8375 | E-mail: marianatavares95.mt@gmail.com

Nathan Bezerra de Lima

Escola Politécnica de Pernambuco | Universidade de Pernambuco | Tel.: (81) 98302-0596 | E-mail: limanathan7@gmail.com

Yêda Vieira Póvoas

Escola Politécnica de Pernambuco | Universidade de Pernambuco | Tel.: (81) 3184-7566 | E-mail: yeda.povoas@gmail.com

Ambiente Construído

Revista da Associação Nacional de Tecnologia do Ambiente Construído

Av. Osvaldo Aranha, $99-3^{\circ}$ andar, Centro

Porto Alegre - RS - Brasil CEP $90035-190$

Telefone: +55 (51) 3308-4084

Fax: +55 (51) 3308-4054

www.seer.ufrgs.br/ambienteconstruido

E-mail: ambienteconstruido@ufrgs.br 